\title{
Green public procurement and multiple environmental objectives
}

\author{
Sofia Lundberg ${ }^{1}$ (D) Per-Olov Marklund ${ }^{2}$
}

Received: 12 May 2017 / Revised: 24 October 2017/ Accepted: 19 December 2017 /

Published online: 3 January 2018

(C) The Author(s) 2018. This article is an open access publication

\begin{abstract}
Policy makers can employ different instruments to address environmental policy objectives, and the guiding principles for a consistent system of environmental policy are (1) the policies should be effective, (2) there should be one objective per instrument, and (3) multiple objectives and multiple policy instruments must be mutually independent of each other. This paper evaluates these three principles for green public procurement (GPP). As an illustrative example, the analysis refers to the Swedish policy of using public purchase of organic foods as a policy instrument to increase the certified organic agricultural area as a share of the total agricultural area. Our analysis shows that GPP fails to satisfy principles (1) and (3), and the only way to satisfy principle (2) is then to have just one objective with the procurement, i.e., to run the operations. GPP might still have a positive environmental impact, but, if applied, the procuring authority has to be very specific with the one-to-one matching of criterion and objective.
\end{abstract}

Keywords Environmental policy · Organic food · Public contracts · Public procurement $\cdot$ Purchasing $\cdot$ Sustainable procurement $\cdot$ Tinbergen rule

JEL Classification D44 $\cdot$ H57 $\cdot$ Q18

Financial support from the Swedish Competition Authority is gratefully acknowledged.

Sofia Lundberg

sofia.lundberg@umu.se

Per-Olov Marklund

pelle.marklund@konj.se

1 Department of Economics, Umeå School of Business and Economics at Umeå University, 90187 Umeå, Sweden

2 The National Institute of Economic Research (NIER), 10362 Stockholm, Sweden 


\section{Introduction}

"While research and development is in progress to improve and deploy cleaner and more efficient technologies, it is also important to influence our consumption and production patterns so as to minimise the damage caused to the environment while maintaining an economic equilibrium at the same time. GPP was introduced as part of an effort to take some concrete steps in this direction." The European Commission on why there is a need for Green Public Procurement (GPP). ${ }^{1}$

Policy makers can employ different instruments to address environmental policy targets. Recently, and as illustrated by the above quotation from the European Commission, public procurement has been highlighted and promoted by politicians as such an instrument. ${ }^{2}$ This is an ongoing worldwide trend (see, e.g., Tukker et al. 2008; Fischer 2010; Qiao and Wang 2011). In 2014, nearly 84\% of the OECD members had developed a national strategy to support public procurement as an environmental policy instrument (OECD 2015). Purchasing processes by which public authorities procure products with a reduced environmental impact but that are perfect substitutes in all other dimensions formally defines green public procurement (GPP). ${ }^{3}$

The purpose of this paper is to assess whether GPP can be used to effectively achieve multiple environmental objectives, given that the real cause of an authority's procurement is the need for goods, services, or public works in order to carry out its operations. Public authorities implement GPP by considering environmental concerns when allocating contracts to private suppliers. The allocation mechanism is competitive tendering, and these concerns may be expressed as environmental requirements on the producer (potential supplier), the production process (vertical dimension), or the supply of the good, service, or public work. Consequently, the environmental performance of the potential supplier and the product are parts of the quality offer, i.e., the auction rule takes the form of multidimensional bidding with a price bid and a quality offer. ${ }^{4}$ Throughout this paper, there will be references to two sectors identified by the European Commission as priority sectors for implementing GPP-internal regular cleaning services (the sector is Cleaning Products and Services) and food (the sector is Food and Catering Services). ${ }^{5}$

The arguments in favor of using GPP as an environmental policy instrument is based on the purchasing power of the public sector (European Commission 2016). In 2013, public expenditures in EU Member States were $13.7 \%$ of the GDP on

\footnotetext{
${ }^{1}$ http://ec.europa.eu/environment/gpp/faq_en.htm\#general2, accessed September 24, 2017.

2 http://ec.europa.eu/environment/gpp/benefits_en.htm, accessed April 3, 2017.

3 http://ec.europa.eu/environment/gpp/what_en.htm, accessed April 3, 2017.

4 See, e.g., Che (1993) or Nishimura (2015) for more on multidimensional auctions.

5 There are in total 21 sectors. The Commission states that "The priority sectors were selected through a multi-criteria analysis including: scope for environmental improvement; public expenditure; potential impact on suppliers; potential for setting an example to private or corporate consumers; political sensitivity; existence of relevant and easy-to-use criteria; market availability and economic efficiency." See http://ec.europa.eu/environment/gpp/gpp_criteria_en.htm, accessed September 12, 2017.
} 
average. ${ }^{6,7}$ In the exercising of this power, GPP is considered to be an important instrument to achieve objectives that are related to climate change, resource use, and sustainable production and consumption (European Commission 2016). The OECD (2013) suggests that GPP contributes to national and international environmental objectives and that it is a major driver for innovation and a vehicle for economic growth. Based on the political ambitions, GPP is clearly seen as a political environmental instrument that can be designed to target multiple objectives.

The question of whether GPP can be used to achieve a certain objective effectively has previously been addressed in a general manner. In a seminal paper, Marron (1997) concludes that public procurement is an imperfect environmental policy instrument. Lundberg et al. (2016) provide a more nuanced picture of GPP by developing the work of Marron (1997) to consider the auction process and the potential bidders' decision of whether or not to participate in the procurement and to submit a tender. The results of these previous studies have all suggested that GPP is an ineffective instrument for meeting the stated environmental goals. However, these studies did not specifically address the possibility of using GPP to target several environmental objectives simultaneously in one and the same procurement auction. An important question, then, is if such a possibility might motivate the use of GPP as an environmental policy instrument. In the present paper, we add to this literature by explicitly considering the multiple-objective feature of GPP.

It is entirely possible to address many different environmental objectives within the same procurement auction, and this is often the case in practice. The ambition might be to achieve more than one objective by stipulating one single environmental requirement, e.g., when procuring foods (Scenario 1 in Sect. 3.1). The requirement might be that the delivered food must meet certain criteria on organic production, and this might expressed as asking for specific labeling of organic products (or similar). Additionally, asking for organic food can be a means to achieve other objectives. As an example, in February 2017 the Swedish Government presented a national food strategy with the main aim to increase food production and to contribute to a competitive food chain characterized by increased employment, exports, innovation, and profitability, all while achieving relevant environmental objectives (Government Bill 2016/17:104). A certain orientation within the strategy is, according to the Swedish Government's action plan (The Swedish Government 2017), that $30 \%$ of Swedish agricultural land be certified organic farmland by $2030^{8}$ and that $60 \%$ of public food consumption be certified organic products by $2030 .^{9}$

\footnotetext{
6 The share of $13.7 \%$ is lower than earlier estimates, which were about $19 \%$, because spending by utility companies is now excluded (European Commission 2016).

7 European Commission, http://ec.europa.eu/DocsRoom/documents/11022?locale=en, Public Procurement Indicators 2013. Countries with the highest share of GDP were the Netherlands (22.7\%), Finland $(17.8 \%)$, and Sweden (16.3\%). Countries with the lowest share were Cyprus $(6.6 \%)$, Greece (8.9\%), and Ireland $(9.9 \%)$. The median was about $12 \%$.

8 Organic production involves cultivation and animal husbandry while striving for environmental consideration, management of resources, and a high degree of self-reliance (Government Communication 2006).

9 Relevant Swedish environmental quality objectives for the orientation for organic production and consumption are, according to Government Communication (2006), primarily the following: A varied
} 
The ambition with GPP might also be to achieve more than one objective by stipulating several different requirements, e.g., when purchasing internal cleaning services (Scenario 2 in Sect. 3.1). According to Lundberg et al. (2015), studying public procurement of cleaning services in Sweden, this might include requirements related to environmental management systems, eco-labeling of the products used, eco-driving and performance of vehicles, the use of chemicals, or the way in which the cleaning service has to be carried out. Turning back to our food example, and based on Swedish data, green criteria for food procurement might include organic food, recycled packaging, the use of aquaculture and marine products, integrated production, and animal welfare (Lundberg and Marklund 2013).

Two guiding principles when designing effective environmental policies are the following. First, policy instruments should be designed to operate as close to the source of the environmental problem(s) as possible, i.e., they should target the source as directly as possible. It follows from this that it is motivated to study GPP in the framework of a single environmental requirement and several, i.e., a multiple set of, environmental objectives. Second, the number of policy instruments should equal the number of objectives, i.e., what the literature refers to as the Tinbergen Rule (Tinbergen 1952). This rule leads us to ask whether we should regard GPP as a single policy or a multiple policy instrument.

The current paper contributes to the scarce number of studies that consider GPP from an economics perspective. Evaluation of the economic consequences of using GPP as a strategic instrument to pursue environmental objectives is easily motivated and important because it takes its point of departure in the fact that all resources are scarce and that society must conserve them in order to create a sustainable future. Conserving scarce resources includes environmental, energy, and climate policies that actually have an impact and that the impact is achieved in a cost-effective manner. ${ }^{10}$ It is in this perspective that the evaluation and potential of GPP as an environmental policy instrument should be understood.

The general conclusion that follows from the analysis is that GPP is not an effective environmental policy instrument, and this conclusion holds even if consideration is given to the multi-objective character of GPP.

The rest of the paper is organized as follows. In the next section, the literature on GPP as an environmental policy instrument is reviewed. In Sect. 3, GPP is discussed in relation to some guiding principles for a consistent system of environmental policy instruments. One of the principles is referred to as the Tinbergen Rule, which is formally outlined in Sect. 4. Finally, in Sect. 5 some concluding remarks are provided.

\footnotetext{
Footnote 9 continued

agricultural landscape, a rich diversity of plant and animal life, and a non-toxic environment as well as good quality of groundwater, zero eutrophication, and reduced climate impact.

${ }^{10}$ Note that cost-effectiveness is regarded from the socioeconomic perspective. This can be, and often is, very different from what is regarded as cost-effective from the perspective of a single firm or organization.
} 


\section{The literature on GPP as an environmental policy instrument}

GPP represents a relatively new area of research (Testa et al. 2012). Much of the emerging literature is not based on a socioeconomic perspective, and it does not take into account the scarcity of resources or opportunity costs. Studies tend to have a "the more the better" approach to GPP, some of them describing GPP initiatives at the national level (Swanson, et al. 2005; Geng and Doberstein 2008; Stage and Arvidsson 2012), some providing guidelines (Parikka-Alhola 2008; Tarantini et al. 2011), and others reporting GPP uptake (Palmujoki et al. 2010; Testa et al. 2012). However, none of these studies include the effect or effectiveness perspective, i.e., the environmental impact or the correction of market failures, respectively.

The existence of market failures, e.g., negative externalities and overuse of public goods, motivates the use of environmental policy. Market failures are themselves signs of wasting of resources. The purpose of policies is then to correct for these failures and to balance the correction between benefits and costs. This balance involves setting proper environmental objectives (the benefits) and choosing effective policy measures to achieve the objectives (the costs) in order to maximize welfare with respect to environmental, social, and economic sustainability.

Based on the socioeconomic perspective, ${ }^{11}$ Lundberg and Marklund (2013) establish that GPP is not a cost-effective environmental policy instrument. One reason is that GPP should be regarded as an administrative/quantitative policy instrument. ${ }^{12}$ That is, if economic instruments can be used instead, GPP is not the least costly policy for reducing environmental problems. However, there might be situations were administrative/quantitative policy measures are preferred to economic instruments, e.g., when there is an urgent need to quickly reduce very hazardous pollutants. ${ }^{13}$ In this case, society might avoid costs in terms of avoided environmental damages (i.e., in terms of reduced benefits). That is, the benefits from implementing an environmentally effective policy instrument might outweigh the cost of not using a cost-effective instrument. This opens up for further consideration of the use of GPP as an instrument of policy.

Within a static and partial market equilibrium model, Marron (1997) theoretically analyzes the environmental impact from the public sector pursuing a substitution policy. This means that the public sector pursues a green purchasing policy by acting as an off-the-shelf consumer that buys a green product instead of a

\footnotetext{
11 A strand of economics literature not discussed in this paper includes studies that focus on deriving and analyzing design issues related to combinatorial auctions for sustainability in transportation (Basu et al. 2015) and scoring rules (Lundberg and Marklund 2011).

12 An administrative policy instrument refers to, e.g., regulations, or in a public procurement perspective, to specifications of usage of materials and production methods. A quantitative instrument can refer to limitations or quotas of pollution. In contrast to economic (market based) and quantitative instruments, administrative instruments regulate how the producer or consumer should reduce their environmental impact.

13 This can be referred to as a "rule of thumb" suggested by Weitzman (1974). Administrative/ quantitative policy instruments might be preferable if the marginal damage of pollutants rises sharply relative to the marginal abatement cost, whereas an economic instrument (e.g., a tax) might be preferable if the marginal abatement costs rise sharply relative to the marginal damage.
} 
conventional brown one. The model in Marron (1997) also considers private demand for the same green and brown products. The green public purchasing policy will, if the sector is a large buyer, result in increased relative prices on green products. Marron shows that market response to the public sector's substitution policy will depend on the price elasticity of supply and demand. For an environmental effect, producers must be insensitive to price changes on both the brown and green markets. At the same time, private consumers must be sensitive to price changes on both markets. Due to the change in relative price, a subset of the private consumers will replace green products with brown ones, resulting in increasing environmental pressure. This implies that the prerequisite for procurement as an environmental policy instrument to have a net effect on emissions is market specific and largely an empirical matter.

The Swedish agricultural policy is partly an example of a substitution policy. More particularly, in 2017 the Swedish Government presented a food policy bill stating the ambition that the organic share of the public sector's food consumption should be $60 \%$ by the year 2030 (Swedish Government 2017). Prior to the introduction of this bill, this had been part of a strategy to increase the domestic share of agricultural land that is certified for organic production (Government Communication 2006). The public sector buys (green) organic foods instead of (brown) conventional foods off-the-shelf. However, a crucial condition stated by Marron (1997) is not met here. The public sector is not a large buyer because it accounts for only about $4 \%$ of the foods market in Sweden. From a theoretical perspective, therefore, the public sector's purchases of organic foods cannot be expected to have any significant impact on the foods market and thus, in the long run, no significant impact on domestic agriculture's conversion to organic production. However, this lack of impact is not empirically confirmed. Additionally, as shown by Jörgensen (2012), in Sweden the price of an organic food basket is on average about $65 \%$ higher than the price of a conventional food basket. This means that the procuring authority must pay a price premium whatever the reason for buying organic food is. One major reason for the higher price is the lower productivity in organic agricultural production. ${ }^{14}$

Lundberg et al. (2016) develop the work of Marron (1997) by adding the auction process and the potential bidders' decision of whether to participate in the procurement or not. In their work, GPP is considered a transformation policy with the purpose of directly controlling potential suppliers' investments in greener production processes and/or products. This reinforces the picture of an imperfect instrument as shown by Marron (1997). That is, for public procurement to be effective as an environmental policy instrument, the conditions regarding the markets must be advantageous.

Furthermore, for the first time the positive link between the stringency of green criteria stipulated by the procurer in the call for tender and potential suppliers' costs to adjust to this call is made transparent (Lundberg et al. 2016). The more stringent the

\footnotetext{
14 In Sweden, organic grain harvests are 50-60\% of conventional ones (Swedish University of Agriculture Sciences 2010). According to Erdmenger (2003), organic farming utilizes around 10\% more land compared to conventional farming, whereas a recent study estimates that an average German organic diet requires about $40 \%$ more land than its conventional counterpart (Treu et al. 2017).
} 
criteria, the more costly the adjustments the suppliers have to make will be if they want to participate in the procurement auction, but at the same time there will be greater scope for reduced emissions. The adjustment cost, e.g., the investment in greener technologies, will be reflected in the bids (if the potential suppliers decide to submit bids). Hence, again the public sector must pay an environmental price premium. The more stringent the green criteria the authority stipulates, the higher the premium will be. Also, the more extensive and complicated it is for potential suppliers to adjust to a green criterion, the higher their transaction costs will be, ${ }^{15}$ which they will transfer to the contracting authority through the bids. Therefore, it is understood that a multiple set of binding green criteria will lead to a higher price premium compared to what only one criterion will lead to, all other things being equal. ${ }^{16}$

The price premium is an additional factor that possibly contributes to GPP not being an effective environmental policy instrument. This is linked to the public sector's, i.e. the procuring authority's, budget and conflicting objectives. If an authority has a fixed budget to run its operations, stringent green criteria will be associated with opportunity costs. Therefore, if the authority wants to contribute significantly to a better environment, e.g., to encourage potential suppliers to cause less environmental damage through cleaner production processes and greener products, the authority must refrain from something else, for example by reducing the standard or supply of public services.

The overall policy implications are basically valid for every procuring authority and for every procurement. When implementing GPP, an authority should base its decision on existing policy instruments targeting the same objectives, the authority's market power, and the elasticities of supply and demand in the private market. In addition, each procuring authority must decide how much of a price premium it is willing to pay, i.e., how strict the green criteria should be and what the authority is willing to refrain from in order to pay the premium.

Although the theoretical studies by Marron (1997) and Lundberg et al. (2016) establish that GPP fails to function effectively as an environmental policy instrument, the implementation of GPP might still have a positive environmental impact. ${ }^{17}$ The magnitude of the impact is partly dependent on the number of bidders investing in greener technologies and their technologies' environmental standard prior to the investments, which altogether is a matter for empirical study. As mentioned earlier, and illustrated below, there are now a few studies that empirically address the functioning of GPP as an environmental policy instrument. However, currently there is no conclusive empirical evidence of GPP actually having had any significant positive environmental impacts.

\footnotetext{
${ }^{15}$ Suppliers' transaction costs might be associated with bid preparation and administration. In addition to the price premium, the procuring authorities will also face transaction costs in terms of the need for information and competence.

16 This also means that studies only counting the number of call for tenders including at least one green criteria, i.e. GPP uptake, are pointless from a socioeconomic and sustainability point of view because they are only considering procurement that includes green criteria. However, green criteria in the call for tender do not necessarily lead to any environmental impact if they are too weak (green washing).

17 A policy instrument having positive environmental impact does not necessarily represent an effective means of governance
} 
For instance, Simcoe and Toffel (2015) analyze the influence on the private sector of municipal procurement under the US Green Building Council's Leadership in Energy and Environmental Design (LEED). They find little, if any, evidence that GPP has been influential. Lundberg et al. (2015) analyze the impact of GPP on potential suppliers' behavior by using field data from Swedish cleaning services. The results indicate that there has only been a weak impact from environmental requirements made by the procuring authorities, possibly because suppliers already meet the requirements. The green requirements are too weak in relation to what the market can offer, i.e., the current standard.

To achieve environmental impact, it is necessary that the requirements go beyond the market's current environmental standard. Building on this result, Lundberg and Marklund (2017) test the hypothesis that the price premium the public authorities pay for implementing GPP is zero. Generally, they cannot reject the hypothesis.

However, there are still aspects of GPP that have not been studied before. One of them is the multiple-objective feature, which allows for addressing many environmental objectives in one and the same procurement auction (call for tender), and it is possible to argue that this broad feature motivates the implementation of GPP from a socioeconomics point of view. In this paper, we address this question. However, to do that properly, we first need to know more about how GPP is generally implemented.

\section{Principles of policy instruments}

Three general guiding principles that are helpful in designing effective environmental policies are, following Mundell (1968), (1) the policy instruments must be effective, (2) the number of policy instruments must equal the number of environmental objectives, and (3) multiple objectives and multiple policy instruments must be mutually independent. The first principle means that the policy instrument should be designed and implemented so as to have the needed level of environmental impact. In Sect. 3.1, GPP is considered in accordance with principles (1) and (2), and in Sect. 3.2 principles (2) and (3) are scrutinized more closely by using GPP as an example.

\subsection{GPP with multiple objectives}

To be effective, environmental policy instruments should be designed so that they are applied as close to the source of the environmental problem as possible. For instance, if pollution from carbon dioxide were the problem, a cost-effective measure would be to impose a tax on substances including carbon, i.e., gasoline.

Public procurement is a multiple-objective instrument. It aims at fulfilling a need (the primary objective), such as providing food or milk to schoolchildren, and, as add-on objectives, the procuring authority might require the food to be organic, transported in a specific way to limit pollution, packed in recycled material, etc. Keeping the basis of the first principle in mind, the multiple-objective feature of GPP can be illustrated as in Fig. 1 and in the two following scenarios. In Scenario 1, 


\section{Scenario 1}

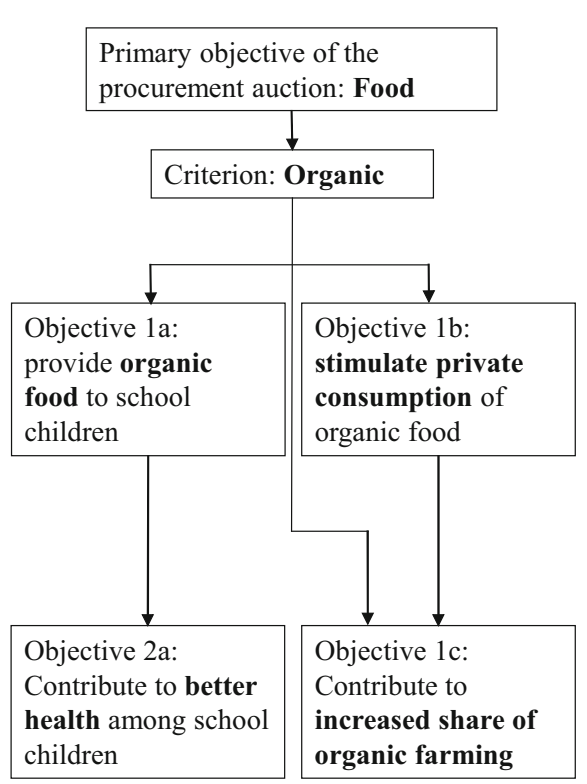

\section{Scenario 2}

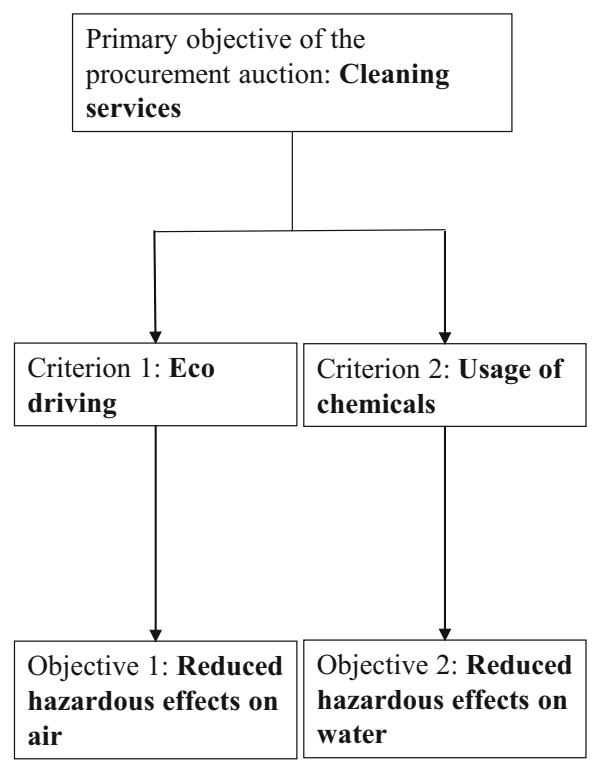

Fig. 1 GPP with multiple objectives

GPP targets a set of multiple objectives with one criterion. In Scenario 2, GPP targets a set of multiple objectives with a set of multiple criteria.

Sweden has long had the ambition to increase consumption of organic foods and to increase the share of arable land certified for organic food production. In 2006 the Swedish Parliament decided upon a goal that $20 \%$ of the agricultural land area in Sweden be certified as organic by the end of 2010. The aim was to increase domestic organic production and, as such, to contribute to several of the national environmental quality objectives (Government Communication 2006). This was recently manifested by the national food strategy (Swedish Government 2017), e.g., that $60 \%$ of public food consumption and $30 \%$ of the agricultural area be certified organic by 2030 . It follows that public procurement of food is a means to target the arable land objective (Box 1c in Scenario 1 in Fig. 1). Public authorities put the policy to practice by stipulating one single environmental criterion, i.e., organic quality, when procuring foods, e.g., cereal and other grain products. The basic level of technical specification is that these products shall comply with the criteria set out in the European Organic Regulations (EC) 834/2007 of 20 June 2007 on organic production and the labeling of organic products. ${ }^{18}$ The political reasoning in the design of the policy instrument following the decision from 2006 is that the public

\footnotetext{
18 Criteria are divided into three ambition levels-basic, advanced, and spearhead. See the National Agency for Public Procurement, and the criteria library, http://www.upphandlingsmyndigheten.se/en/ sustainable-public-procurement/sustainable-procurement-criteria/food/bread-flour-grain-sugar-and-rice/ cereals-and-other-grain-products/eu-organic-product/\#bas.
} 
sector purchasing policy should also influence the health of the school children (1a in Scenario 1 in Fig. 1) and by leading by example should stimulate private consumers to follow (1b in Scenario 1 in Fig. 1).

Further, the main of purpose with procurement of foods as a policy instrument is to achieve the organic land objective. In reality, this objective is in turn an instrument to improve the environment, e.g., to increase the diversity of plant and animal life. The longer the series of linked objectives - the further away from the primary objective, in this case the public consumption of organic foods-the more indirectly the GPP will be able to govern.

For instance, public procurement of organic foods does not directly govern farmers' share of certified organic land area. For this aim, it would probably be more effective to directly subsidize farmers to convert to organic farming (Jörgensen 2012). For example, if the Swedish public sector's increased demand for organic foods were to be mainly satisfied through imports, then such demand would have little, if any, impact on the share of certified organic land area in Sweden.

The second guiding principle, that the number of policy instruments should equal the number of environmental objectives, can be discussed by referring to Scenario 2 in Fig. 1-in this case using the example of procurement of internal regular cleaning services. If GPP policies are implemented according to this approach, they have the potential to govern less indirectly. There is no limitation on how many environmental criteria an authority can specify in the tender documents when procuring goods or services. It is, therefore, possible to set up multiple environmental objectives and address each objective with a single environmental criterion. In Scenario 2 this is exemplified with a procurement where there is one criterion per objective, and the requirement of eco-driving (Criterion 1) is linked to the objective of reduced hazardous effect on the air (Objective 1), and the requirement related to the usage of chemicals (Criterion 2) aims at reduced hazardous effect on water (Objective 2).

If we turn back to Scenario 1 and apply the Scenario 2 approach, the public sector's purchases of organic foods should be motivated by a single objective as close to public consumption of organic foods as possible, such as the well-being and health of those who actually eat the food. ${ }^{19}$ In this case, the achievement of the objective does not depend on the origin of the foods, i.e. whether it is imported or produced domestically, and the effect on domestic farming converting to organic production is thus very uncertain. The policy implication is that the procuring authority has to be very specific with the one-to-one matching of criterion and objective.

If we assume that a contracting authority has several different environmental objectives in sight, according to Fig. 1, and that the authority specifies a unique environmental criterion for each of the objectives in the call for tender, as illustrated in Scenario 2, it follows that a reasonable question is if GPP in this particular

\footnotetext{
19 Here we follow the motivation of the Swedish Government decision from 2006 and assume that organic foods have positive effects on peoples' health, the environment, and the climate. This view is not entirely scientifically unchallenged. In terms of nutritional content in organic foods, see, e.g., Baránski et al. (2014), Smith-Spangler et al. (2012), and Dangour et al. (2009). In terms of environmental impact from pesticides, see, e.g., Tuomisto et al. (2012), Wilcox (2012), and Bahlai et al. (2010).
} 
procurement should be regarded as a multiple set of environmental policy instruments working in parallel, or if it should be considered a single policy instrument. This question is answered in the following section.

\subsection{Does GPP constitute a consistent policy system?}

The previous section shows that a specific procurement might target several objectives. However, the primary reason for public procurement, i.e., the primary and binding objective, is to meet the needs the contracting authorities have in order to be able to conduct their operations, for example, building roads or providing health care or education. The initial reason for the actual procurement process is that the procuring authority (or rather the public authority it represents) has decided not to run operations in-house and instead has sought an external provider through the use of a competitive procurement mechanism to get the best combination of price and quality, i.e. best value for the money.

The main objective of the procurement auction, e.g., buying food for schoolchildren or finding an external provider to run a nursing home for the elderly (Bergman et al. 2016), is independent of the environmental policy objective of the same procurement, but the reverse does not apply. For instance, a procuring authority can buy food for schoolchildren without stipulating it to be organic, but the authority cannot stipulate the food to be organic without buying it. The same logic applies to internal regular cleaning services, and the procurement of the service can be with or without demanding specific green criteria. The signal to the cleaning service suppliers to invest in greener technology is, however, conditioned on the service being outsourced in contrast to being produced in-house.

It follows that public procurement as an environmental policy instrument does not fulfill the third guiding principle for consistent policy, that the policy instruments are required to be mutually independent from each other. The conclusion is that GPP targets environmental objectives indirectly. Hence, GPP is one single policy instrument addressing multiple objectives, and this is theoretically formalized in the next section.

\section{GPP and the Tinbergen Rule}

The principle that the number of instruments has to coincide with the number of objectives in order to effectively achieve all objectives is known as the Tinbergen Rule (1952). In Sect. 4.1, this rule is formally outlined and related to GPP. GPP is always limited by a budget, which might affect the ability to comply with the Tinbergen Rule, as illustrated in Sect. 4.2.

\subsection{Formal outline of the Tinbergen Rule and GPP}

The Tinbergen Rule expresses the mathematical outcome that a system of equations and unknowns only has a unique solution when the number of equations and unknowns are equal. In this section, we reproduce some of the formal outline of the 
static policy solutions that are predicted by the Tinbergen Rule as presented in Mundell (1968). ${ }^{20}$

Assume that there are two effective policy instruments, denoted $a$ and $b$, and three objective variables, $X=X(a, b), Y=Y(a, b)$, and $Z=Z(a, b)$. Assume further that the two instruments are implemented to achieve these predetermined policy objectives according to:

$$
\begin{aligned}
& X_{0}=X(a, b) \\
& Y_{0}=Y(a, b) \\
& Z_{0}=Z(a, b)
\end{aligned}
$$

This is illustrated in Fig. 2, assuming linearity between $a$ and $b$.

With two policy instruments, you could always achieve one objective, e.g., $X_{0}$, with an endless number of combinations of $a$ and $b$. There are an infinite number of solutions because the system is overdetermined. It is also possible to achieve two objectives, e.g., $X_{0}$ and $Y_{0}$. However, in this case there is only one combination of $a$ and $b$ that complies with the ambition of achieving both objectives. There is a unique solution at $\alpha$, and the system is determined.

If a third policy objective, $Z_{0}$, is introduced, however, you have to refrain from achieving at least one objective. For instance, at $\alpha$ when $X_{0}$ and $Y_{0}$ are achieved, $Z_{0}$ is not. If $Z_{0}$ is to be achieved, either $X_{0}$ or $Y_{0}$ must be abandoned, as illustrated by the solutions $\gamma$ and $\beta$, respectively. The system is underdetermined.

This outcome can be related to Scenario 1 in Fig. 1, that of public purchase of organic foods. In this case, a single policy instrument, i.e., GPP, is used to achieve multiple objectives. For instance, consider an authority that runs an elementary school and that is obliged to serve free food to the schoolchildren. ${ }^{21}$ The reason why the authority is purchasing food at all is to be able to feed the children, and the procurement auction for buying the foods is thus the actual policy instrument. Suppose that there is a political decision that all foods must be organic. To meet this obligation, the authority designs the call for tender to be suited for this purpose and procures, among other things, a well-composed mix of foods that meet the definition of being organic. The quality of the mix refers to an objective that stipulates, for example, a certain nutrient level, $X_{0}$. However, a secondary objective is to increase the share of organic farmland in the region to a certain extent, $Y_{0}$. Referring to the Tinbergen Rule, this represents a system of equations that is underdetermined because it comprises two objectives but only one policy instrument, $X_{0}=X(a)$ and $Y_{0}=Y(a)$, where $a=$ procurement of food. Hence, the second guiding principle of effective policies mentioned above, that the number of policy instruments must equal the number of objectives, is not fulfilled.

Furthermore, the third principle of mutual independence is not fulfilled. The policy instrument in this case, procurement of foods, is actually the primary

\footnotetext{
${ }^{20}$ We use the same notation.

21 According to the Swedish School Act, since 1997 it has been obliged to serve the schoolchildren with a free lunch.
} 


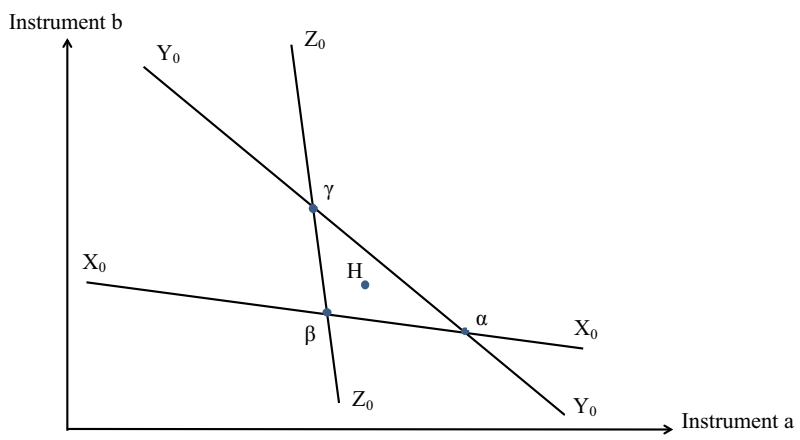

Fig. 2 Two instruments and three objectives. Source: Mundell (1968)

objective. As an objective, it is not mutually independent of the objective of organic foods. Again, the procuring authority can buy food without stipulating it to be organic, but the authority cannot stipulate the food to be organic without buying it. The same type of reasoning can be applied to any other service, good, or public work that the public sector has chosen to outsource using public procurement auctions instead of producing in-house.

\subsection{GPP and budget constraints}

If a public procurement is to be regarded as one single policy instrument, it should not be used to attempt to achieve more than one single objective. In relation to practice, this weakness is augmented if consideration is also given to the procuring authority's budget restriction as illustrated in Fig. 3.

Even if we wrongly assume that GPP can be considered as two instruments, $a$ and $b$, and that they can be used in order to effectively achieve two objectives simultaneously at point $\alpha$, this is not necessarily sufficient for an effective outcome. Again, if the primary and "binding" objective is to provide organic food with quality $X_{0}$, and there is a secondary environmental objective level, $Y_{0}$, the best

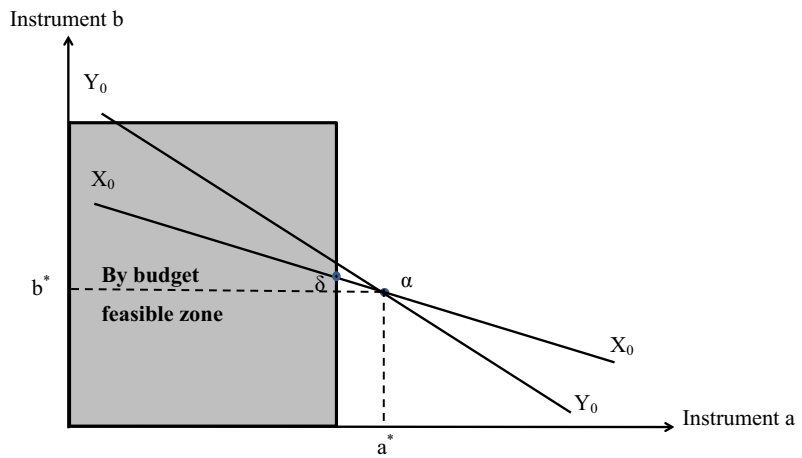

Fig. 3 Budget constraints. Source: Mundell (1968) 
solution due to the budget restriction would be at $\delta$. In this case, GPP fails to achieve the latter objective. With unrestricted resources, the effective outcome $\alpha$ is possible, but with restricted resources it is not.

It seems reasonable to consider the budget to play a decisive role for GPP and its potential to have an environmental impact in practice. On this subject, there are only a few empirical studies available. The literature discussed above indicates that the environmental criteria in the procurement auctions studied are not binding. A plausible explanation for this result is the binding budget constraint, and the procuring authorities have to prioritize what they are primarily designed to do, namely, to run their operations.

\section{Concluding remarks}

Policy makers can employ different instruments to address environmental policy targets, and public sector purchasing power, i.e., public procurement, is found on the list of plausible instruments around the world. The guiding principles for a consistent system of environmental policy are (1) that the policy instrument must be effective, i.e., actually have an environmental impact to the necessary degree; (2) that each environmental objective must be targeted with a single policy instrument, i.e., "one objective, one instrument", and (3) that multiple objectives and multiple policy instruments must be mutually independent (Mundell 1968). This paper evaluates these three principles for GPP as an environmental policy instrument.

The analysis of principle (1) is largely a matter of empirical research, and the few studies available indicate that GPP has had only a weak impact at best. As an illustrative example, the analysis refers to the Swedish policy of using public purchase of organic foods as a policy instrument to achieve the objective of increasing the domestic share of certified organic agricultural land. In this case, the objective is targeted indirectly and, therefore, can be expected to be less effective. A direct subsidy to the farmers for transition to organic production is likely to be more effective. The Swedish public sector's purchase of organic foods might still have a positive impact on the share of organic agricultural land in Sweden, but this is a matter for further empirical research.

Our analysis also shows that GPP fails to satisfy principle (3), that multiple objectives and multiple instruments must be mutually independent of each other. In turn, this means that GPP should be regarded as a single policy instrument. The only way to satisfy principle (2) is then to have just one objective with public procurement, i.e., to procure the necessary good, service, or public work with the sole aim of running the operations.

Earlier theoretical research has found that GPP is neither a cost-effective nor an objectively effective environmental policy instrument. In this study, we have tackled the GPP policy issue from a different angle, but we still arrive at the same conclusion.

From a policy perspective, and with environmental impact in mind, the procurements should focus on a single objective as close to the subject matter of the procurement as possible. Consequently, the policy implication is that the procuring 
authority has to be very specific with the one-to-one matching of criterion and objective. Furthermore, when environmental concern is a part of the allocation of public contracts, the authorities should be transparent in the call for tender in terms of the link between the green criteria and the environmental objective. This will, among other things, make it easier to evaluate the impact, i.e., the link between specific green criteria and their impacts on the environment, climate, and health. This will also make it easier to measure the cost of using public procurement as an environmental policy instrument. It should, however, be noted that even if a specific call for tender reflects a clear linkage between the green criteria and green objectives, an evaluation of the total effect based on the sum of the individual initiatives from all, or a subset of, the contracting authorities is likely to be resource intensive. Thus the coordination problem might, in practice, turn out to be difficult.

Open Access This article is distributed under the terms of the Creative Commons Attribution 4.0 International License (http://creativecommons.org/licenses/by/4.0/), which permits unrestricted use, distribution, and reproduction in any medium, provided you give appropriate credit to the original author(s) and the source, provide a link to the Creative Commons license, and indicate if changes were made.

\section{References}

Bahlai, C. A., Yingen, X., McCreary, C. M., Schaafsma, A. W., \& Hallett, R. H. (2010). Choosing organic pesticides over synthetic pesticides may not effectively mitigate environmen-tal risk in soybeans. PLoS ONE, 5(6), 1-7.

Baránski, M., Srednicka-Tober D., Volakakis N., Seal C., Sanderson R., Stewart G B., Benbrook C., Biavati B., Markellou E., Giotis C., Gromadzka-Ostrowska J., Rembiałkowska E., SkwarłoSońta K., Tahvonen R., Janovská D., Niggli U., Nicot P. \& Leifert C. (2014). Higher antioxidant and lower cadmium concentrations and lower incidence of pesticide residues in organically grown crops: A systematic literature review and meta-analyses. British Journal of Nutrition, 112(5), 794-811.

Basu, R. J., Bai, R., \& Palaniappan, P. L. K. (2015). A strategic approach to improve sustainability in transportation service procurement. Transportation Research Part E, 74, 152-168.

Bergman, M. A., Johansson, P., Lundberg, S., \& Spagnolo, G. (2016). Privatization and quality: Evidence from elderly care in Sweden. Journal of Health Economics, 49, 109-119.

Che, Y.-K. (1993). Design competition through multidimensional auctions. RAND Journal of Economics, 24(4), 668-680.

Dangour, A. D., Dodhia, S. K., Hayter, A., Allen, E., Lock, K., \& Uauy, R. (2009). Nutritional quality of organic foods: A systematic review. The American Journal of Clinical Nutrition, 90(3), 680-685.

Erdmenger, C. (2003). Financial power and environmental benefits. In C. Erdmenger (Ed.), Buying into the environment: Experiences, opportunities and potential for eco-procurement (pp. 116-133). Sheffield: Greenleaf Publishing in Association with GSE Research.

European Commission (2016). Buying green! A handbook on green public procurement, 3rd Edn.

Fischer, E. A. (2010). Overview and issues for congress. CRS Report for Congress. Washington: Congressional Research Service.

Geng, Y., \& Doberstein, B. (2008). Greening Government procurement in developing countries: Building capacity in China. Journal of Environmental Management, 88, 932-938.

Government Bill (2016). En livsmedelsstrategi för Sverige - fler jobb och hållbar tillväxt i landet, kortversion av regeringens proposition 2016/17:104.

Government Communication (2006). Ekologisk produktion och konsumtion - Mål och inriktning till 2010. Regeringens skrivelse Skr. 2005/06:88.

Jörgensen, C. (2012). Mål som styrmedel - målet för den offentliga konsumtionen av ekologiska livsmedel. AgriFood Report 2012:1, Lund. 
Lundberg, S., \& Marklund, P.-O. (2011). The pivotal nature of award methods in green public procurement. Enviornmental Economics, 2(3), 64-73.

Lundberg, S., \& Marklund, P.-O. (2013). Offentlig upphandling eller gröna nedköp? En ESO rapport om miljöpolitiska ambitioner., Expertgruppen för studier i offentlig ekonomi Stockholm: Fritzes.

Lundberg, S., \& Marklund, P.-O. (2017). Influence of green public procurement on bids and prices. Mimeo.

Lundberg, S., Marklund, P.-O., \& Strömbäck, E. (2016). Is environmental policy by public procurement effective? Public Finance Review, 44(4), 478-499.

Lundberg, S., Marklund, P.-O., Strömbäck, E., \& Sundström, D. (2015). Using public procurement to implement environmental policy: An empirical analysis. Environmental Economics and Policy Studies, 17(4), 487-520.

Marron, D. B. (1997). Buying green: Government procurement as an instrument of environmental policy. Public Finance Review, 25(3), 285-305.

Mundell, R. A. (1968). The nature of policy choices. In Mundell R. A. (Eds.), International Economics, ch 14. London: MacMillan.

Nishimura, T. (2015). Optimal design of scoring auctions with multidimensional quality. Review of Economic Design, 19(2), 117-143.

OECD (2013). Mapping out good practices for promoting green public procurement, OECD meeting of Leading Practitioners on Public Procurement, 11-12 February 2013, Paris, OECD Conference Centre.

OECD (2015). Government at a Glance 2015. Paris: OECD Publishing.

Palmujoki, A., Parikka-Alhola, K., \& Ekroos, A. (2010). Green public procurement: Analysis of the use of environmental criteria in contracts. Review of European Community and International Law, $19(2), 250-255$.

Parikka-Alhola, K. (2008). Promoting environmentally sound furniture by green public procurement. Ecological Economics, 68(1-2), 472-485.

Qiao, Y., \& Wang, C. (2011). Issues and challenges in implementing China's green public program. Journal of Environmental Protection, 8(2), 1034-1045.

Simcoe, T., \& Toffel, M. W. (2015). Government green procurement spillovers: Evidence from municipal building policies in California. Journal of Environmental Economics and Management, 68(3), 411-434.

Smith-Spangler, C., Brandeau, M. L., Hunter, G. E., Bavinger, C. J., Pearson, M., Eschbach, P. J., Sundaram, V., Liu, H., Schirmer, P., Stave, C., Olkin, I. \& Bravata, D. M. (2012). Are organic foods safer or healthier than conventional alternatives? A systematic review. Annals of Internal Medicine, 157(5), 348-366.

Stage, J., \& Arvidsson, A. (2012). Technology-neutral green procurement in practice-An example from Swedish waste management. Waste Management and Research, 30(5), 519-523.

Swanson, M., Weissman, A., Davis, G., Socolof, M. L., \& Davis, K. (2005). Developing priorities for greener state government purchasing: A California case study. Journal of Cleaner Production, 13(7), 669-677.

Swedish Government (2017). Regeringens handlingsplan: En livsmedelsstrategi för Sverige - fler jobb och hållbar tillväxt $i$ hela landet, Prop. 2016/17:104. Stockholm.

Swedish University of Agriculture Sciences. (2010). Redovisning av uppdrag om halvtidsutvärdering av Landsbygdsprogram för Sverige 2007-2013. Lund: Swedish University of Agriculture.

Tarantini, M., Loprieno, A. D., \& Porta, P. L. (2011). A life cycle approach to green public procurement of building material and elements: A case study of windows. Energy, 36(5), 2473-3482.

Testa, F., Iraldo, F., Frey, M., \& Daddi, T. (2012). What factors influence the uptake of GPP (Green Public Procurement) practices? New evidence from an Italian survey. Ecological Economics, 82(2), 88-96.

The Swedish Government (2017). En livsmedelsstrategi för Sverige - Fler jobb och hållbar tillväxt i hela landet, Regeringens handlingsplan, Regeringskansliet, Näringsdepartementet.

Tinbergen, J. (1952). On the theory of economic policy. Amsterdam: North Holland Publishing Company.

Treu, H., Nordborg M., Cederberg C., Heuer T., Claupein E., Hoffmann H., \& Berndes G. (2017). Carbon footprints and land use of conventional and organic diets in Germany. Journal of Cleaner Production, 161, 127-142.

Tukker, A., Emmert, S., Charter, M., Vezzoli, C., Sto, E., Andersen Much, M., Geerken, T., Tischner, U., \& Lahlou, S. (2008). Fostering change to sustainable consumption and production: An evidence based view. Journal of Cleaner Production, 16, 1218-1225. 
Tuomisto, H. L., Ian, D. H., Philip, R., \& David, W. M. (2012). Does organic farming reduce environmental impacts? A meta-analysis of European research. Journal of Environmental Management, 112, 309-320.

Weitzman, M. (1974). Prices vs. quantities. Review of Economic Studies, 41(4), 477-491.

Wilcox, C. (2012). Are lower pesticide residues a good reason to buy organic? Probably not. Scientific American. 